\title{
Edad a la cirugía de testículo no descendido y riesgo de cáncer testicular
}

Age at surgery for undescended testis and risk of testicular cancer

Pettersson A, et al. N Engl J 2007;356(18):1835-41.

\section{Objetivo}

Dado que la presencia de un testículo no descendido es un factor de riego para el desarrollo de cáncer de testículo en la vida adulta, los autores estudiaron la relación entre la edad al tratamiento quirúrgico mediante orquidopexia (OP) y el riesgo de desarrollar cáncer de testículo (CT).

Diseño

Cohorte retrospectiva.

\section{Lugar}

Hasta 1975, 16 zonas sanitarias y desde 1987, todas la regiones de Suecia.

\section{Pacientes}

16.983 pacientes del Registro Sueco de Alta Hospitalaria (1965 a 2000) que presentaban diagnóstico de criptorquidia y que hubieran recibido una OP (descenso y fijación testicular) antes de los 20 años de edad.

Evaluación de factores pronósticos y resultados principales

Riesgo -Hazard Ratio $(\mathrm{HR})^{\star}$ de CT estimado mediante la razón de incidencia estandardarizada*- de CT germinal (seminoma, y no seminoma como teratoma, coriocarcinoma, tumor del saco vitelino, carcinoma embrionario y tumores mixtos). Solamente se incluyeron pacientes con CT desarrollado al menos un año después de la cirugía y fueron excluidos los operados luego de los 20 años de edad, en quienes la infertilidad puede ser un factor confundidor.

\section{Resultados principales}

El seguimiento fue de 209.964 personas/año en riesgo. La edad media y mediana de OP fueron similares: $8,6 \pm 3,5$ años y 8,5 años respectivamente. Fueron identificados 56 casos de cáncer de testículo con una razón de incidencia estandardarizada de 2,75 (IC95\% 2,08 a 3,57) cada 10.000 personas en riesgo por año: 2,23 (IC95\% 1,58 a 3,06) en los operados antes de los 13 años y 5,4 (IC95\% 3,2 a 8,53) para aquellos tratados luego de esa edad. EL riesgo de CT fue de casi el doble en los operados luego de los 13 años (HR: 1,99; IC95\% 1 a 3,95). Ver figura 1.

Figura 1: riesgo de desarrollo de cáncer testicular de acuerdo a la edad a la que fue realizada la orquidopexia.

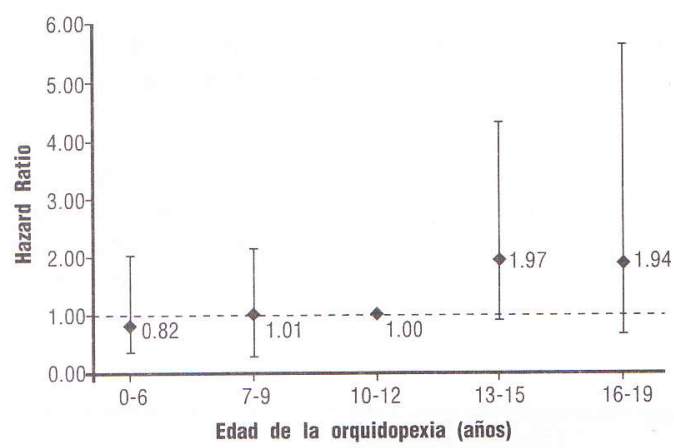

Conclusiones

La OP antes de los 13 años reduce el riesgo de desarrollar CT.

Palabras Claves: Testículo no descendido, cáncer de testículo, orquidopexia. Key Words: undescended testis, testicular cancer, orchiopexy.

Fuente de financiamiento: Sociedad y Consejo Suecos del Cáncer, Fundación Internacional en Medicina Experimental Compagnia San Pablo (Italia) y Centro Italiano para la Investigación del Cáncer.

\section{Comentario}

El testículo no descendido está presente en $1 \%$ de los varones de un año de edad y está en relación con dos trastornos potenciales en la adultez: infertilidad y cáncer de testículo' La edad temprana del tratamiento ha sido siempre relacionada con mejores resultados en el largo plazo, pero todos los estudios publicados mostraron poblaciones muy heterogéneas (edad a la cirugía, tipo de tratamiento médico, localización testicular, biopsia) y dificultad para seguir a estos pacientes en períodos alejados a la cirugía ${ }^{2}$.

Este trabajo, sobre una gran muestra poblacional, informa que realizar la OP luego de la pubertad se asocia a un mayor riesgo a posteriori de CT.

Desafortunadamente y por las características de los registros de las grandes bases de datos de la población sueca, no se pudo definir: 1) si el desarrollo de CT fue ipsi o contralateral a la OP; 2) si el desarrollo de CT está en relación con la localización previa del testículo (intrabdominal, canalicular o inguinal) lo que podría reflejar mayor grado de displasia testi- cular cuanto mas alejado esté el testículo de la bolsa escrotal; 3) si el no descenso testícular era congénito o adquirido -este último grupo muy descrito y revisado en los últimos años, agrega otro factor de confusión ${ }^{3}$; 4) si aquellos que recibieron tratamiento hormonal como único tratamiento tienen también mayor riesgo de desarrollar $\mathrm{CT}$.

\section{Conclusiones del comentador}

Esta nueva evidencia tiene dos valores fundamentales: 1) todos los pacientes sometidos a OP deben conocer esta información para consultar precozmente ante síntomas o signos a nivel testicular que hagan sospechar CT (dolor, agrandamiento, cambio de la consistencia); 2) debe ofrecerse esta información a los adolescentes o adultos jóvenes que consulten por un testículo no descendido no tratado para la elección del tratamiento (orquidectomía contra orquidopexia tardía).

Ver glosario*

Eduardo Ruiz [ Jefe de Servicio de Cirugía Pediátrica. Hospital Italiano de Buenos Aires. eduardo.ruiz@hospitalitaliano.org.ar ] 